\title{
ENTRE EL DEBER SER Y EL SER DEL CRECIMIENTO ECONÓMICO EN MÉXICO: 1980-2020
}

BETWEEN THE DUTY TO BE AND THE BEING OF ECONOMIC GROWTH in Mexico: 1980-2020'

\author{
ERICKA J. ARIAS GUZMÁN ${ }^{2}$ \\ FELIPE CRUZ DÍAZ ${ }^{3}$
}

\begin{abstract}
Resumen: En el presente trabajo se analiza el llamado modelo económico neoliberal, cuáles fueron sus orígenes y sus principios básicos en la determinación del crecimiento económico y cómo fue adoptado primero en las economías desarrolladas como Estados Unidos e Inglaterra y posteriormente en los años ochenta en México, con el propósito de salir de la crisis de la deuda, la hiperinflación y generar las condiciones para un crecimiento económico sostenido con estabilidad macroeconómica. Si bien este objetivo se cumplió parcialmente, generó desigualdad y elevados niveles de pobreza extrema en el país. La política económica del gobierno de Andrés Manuel López Obrador se propuso establecer un modelo 'posneoliberal' en donde el Estado estaría por encima del mercado y sería el encargado de promover el bienestar de los sectores de ingresos más bajos de la población. Sin embargo, no es clara la estrategia que se llevará a cabo para alcanzar este objetivo.

Palabras Glave: crecimiento económico, crisis, desarrollo económico, estabilidad macroeconómica, neoliberalismo y política monetaria.
\end{abstract}

${ }^{1}$ El presente trabajo forma parte del Proyecto Institucional PAIDI 002/20 Debates recientes sobre la metodología económica.

${ }^{2}$ Profesora adscrita al Posgrado de la Facultad de Estudios Superiores Acatlán de la UNAM. Contacto: <erickajudith@yahoo.com>. ORCID: https://orcid.org/00000002-1663-9509.

${ }^{3}$ Profesor adscrito al Posgrado de la Facultad de Estudios Superiores Acatlán de la UNAM. Contacto: <fel_economia@comunidad.unam.mx>. ORCID: https://orcid. org/0000-0003-0600-6940.

Fecha de recepción: 22 de junio de 2020; Fecha de aprobación: 19 de octubre de 2020. 
Aвstract: This paper analyzes the neoliberal economic model, its origins, its basic values in determinates economic growth and how it was first adopted in developed economies such as the United States and England, and in case of Mexico, it was until the 1980 s to get out of the debt crisis, hyperinflation was applied to create the conditions for sustained economic growth with macroeconomic stability, which, although the objective was partially fulfilled, generated inequality and high levels of extreme poverty in the country. The economic policy of the Andres Manuel Lopez Obrador government set out to establish a 'post-neoliberal' model where the State would be above the market and would be in charge of promoting the social welfare of the lower income sectors of the population. However, the strategy that will be carried out to achieve this objective is not clear.

KeYWORDs: economic growth, crisis, economic development, macroeconomic stability, neoliberalism and monetary policy.

Sumario: I. El neoliberalismo; II. El Neoliberalismo en el contexto internacional; III. El Neoliberalismo en México; IV. El neoliberalismo y la alternancia política en México; V. Rumbo al fin del neoliberalismo; VI. El neoliberalismo un experimento fallido en México: entre el deber y el ser; VII. Conclusiones; VIII. Fuentes consultas.

\section{El Neoliberalismo}

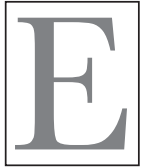

1 concepto de neoliberalismo fue propuesto por primera vez por el economista alemán Alexander Rüstow en 1938 y surgió por la necesidad de agrupar razonamientos teóricos existentes desde la economía clásica cuyas ideas fueron retomadas por Friedrich Von Hayek que materializó en el texto Camino de Servidumbre (The Road to Serfdom) donde criticaba abiertamente el creciente intervencionismo estatal en la conducción de la actividad 
económica de los países más afectados por la crisis económica de finales de los años veinte. Este hecho, propició un intenso debate entre la Teoría de Libre Mercado de Hayek y la Teoría General de la Ocupación, el Interés y el Dinero (The General Theory of Employment, Interest, and Money) de J. M. Keynes quien argumentaba la intervención estatal para promover el crecimiento económico a través del gasto público e incluso, mediante el endeudamiento.

En este sentido, en el neoliberalismo el papel del Estado debe ser únicamente el de garantizar que se establezcan las condiciones de competencia, para que sea el propio mercado quien dirija la actividad económica, tal como lo menciona Hayek en el capítulo VI de Camino de Servidumbre en el que establece que se debe de garantizar el estado de derecho para el correcto funcionamiento de la economía; idea que posteriormente fue retomada por Milton Friedman (quien es considerado el padre del monetarismo) al asegurar que sólo en una verdadera democracia, se pueden generar las condiciones para que el mercado funcione correctamente y se pueda fomentar el crecimiento económico de un país mediante el control de la cantidad de dinero y los precios, restándole importancia al gasto público por considerarlo ineficiente e inflacionario. Por el contrario, para Keynes, el papel del Estado es fundamental para la promoción del crecimiento y desarrollo económicos, ya que afirma que mediante el gasto público, se generan las condiciones necesarias para que un país pueda crecer a un ritmo sostenido.

Por muchos años, este debate prevaleció entre los estudiosos del libre mercado y los teóricos de la intervención del Estado, pero fue a finales de la década de los años setenta con la alianza política y personal de M. Thatcher y R. Reagan, cuando se retomaron las ideas de Milton Friedman respecto a la forma de conducir la política económica como resultado de la crisis de estos años, dando por finalizado el llamado Estado de Bienestar que se siguió desde los Acuerdos de Bretton Woods en 1944. 
Esta alianza fortaleció el poder político y económico de estos dos países, lo que les permitió tener influencia en las decisiones en estos ámbitos, en detrimento de la soberanía de las economías emergentes debido a que instauraron la forma de conducción de la política económica a través del llamado Consenso de Washington de 1988 en el cual, J. Williamson estableció diez propuestas o recomendaciones para que las economías -sobre todo latinoamericanasenfrentaran las crisis de deuda que presentaron en estos años. Estas medidas consistieron principalmente en llevar cabo un ajuste en la estructura fiscal, estabilidad del sistema financiero y variables monetarias, liberalizar el comercio y sistema financiero, garantizar los derechos de propiedad y fomentar la inversión extranjera directa. En resumen, el modelo económico neoliberal que prevalece tiene su origen en una economía de libre mercado, de control de precios y estabilidad macroeconómica, dejando atrás el modelo keynesiano que se aplicó hasta finales de los años setenta.

\section{El neoliberalismo en EL CONTEXto internacional}

A finales de la década de los años sesenta, se inició un proceso de desaceleración económica a nivel mundial lo que evidenció que el llamado Estado Benefactor comenzaba a debilitarse; particularmente, Estado Unidos y Japón comenzaron a presentar problemas de inflación originados por un exceso de demanda en el mercado. A esto se agregó la bonanza de algunos países como resultado del incremento en los precios del petróleo a nivel internacional lo que proveía de liquidez al mercado. Sin embargo, en la mitad de la década de los años setenta, se presentaron tres fenómenos importantes a nivel internacional: 1) el Mal Holandés ; 2) la creación de la OPEP; y 3) las crisis de balanza de pagos propiciada por la salida de capital de los países, lo cual afectó la paridad del tipo de cambio, que a su vez, acentuaron los problemas inflacionarios en los países desarrollados y posteriormente, en los países en 
desarrollo donde se originó además un proceso inflacionario que obstaculizó el pago de la deuda y provocó devaluación del tipo de cambio, déficit público y caída de la actividad económica de estos países.

En este contexto, en Estados Unidos, las ideas de Milton Friedman se volvieron relevantes ya que se centraban fundamentalmente en un estricto control de los precios mediante la contención de la oferta monetaria nominal, la cual incidiría directamente sobre el ingreso nominal y en consecuencia, en los precios; y los efectos de esta política no se verían en el corto plazo ya que como Friedman lo argumentó, un cambio en el indice monetario, puede tener efecto en el crecimiento del producto nominal entre seis y nueve meses posterior a la adopción de esta medida.

En la década de los años ochenta, la política económica se orientó a estabilizar los precios, a controlar la oferta monetaria y las tasas de interés para estimular la inversión y como consecuencia final, la promoción del crecimiento del PIB tal y como lo sugería Friedman en sus diferentes textos.

La Gráfica 1 muestra el comportamiento del PIB y la inflación, en la cual se observa que se cumplió con el objetivo de estabilizar los precios pero el crecimiento del PIB no creció a los niveles esperados, lo que provocó problemas de desempleo, desigualdad y pobreza que es una de las principales críticas que se le han realizado a este modelo económico.

\section{Gráfica 1. Producto Interno Bruto e inflación mundial} (Tasa de crecimiento anual)

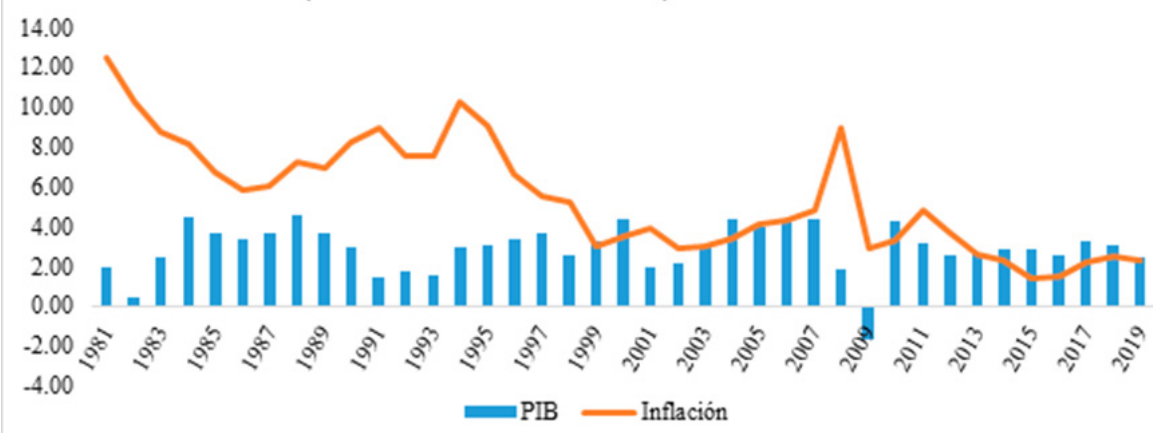


En América Latina, este modelo tuvo su experimento en la dictadura militar en Chile y posteriormente en Argentina, donde la característica principal de estos países es que no eran gobiernos democráticos sino de carácter militar y por lo tanto, el modelo se aplicó de forma impositiva.

En Chile, un grupo de profesores de la Universidad Católica fueron enviados a la Escuela de Chicago para ser formados bajo la tutela de Milton Friedman los cuales fueron denominados Chicago Boys el resultado de su estancia fue un texto denominado El ladrillo en el cual quedó plasmada toda la ideología económica monetarista y neoliberal que sería aplicada en la dictadura militar el cual se convirtió posteriormente en el modelo a seguir en otras economías latinoamericanas. En la gráfica 2 se observa que el resultado fue similar al que se obtuvo en las economías desarrolladas, es decir, se controló la inflación pero el crecimiento del PIB no creció con el dinamismo esperado y los problemas de desempleo, falta de inversión y pobreza fueron más profundos que en aquellos países.

\section{Gráfica 2. Producto Interno Bruto e inflación en América Latina}

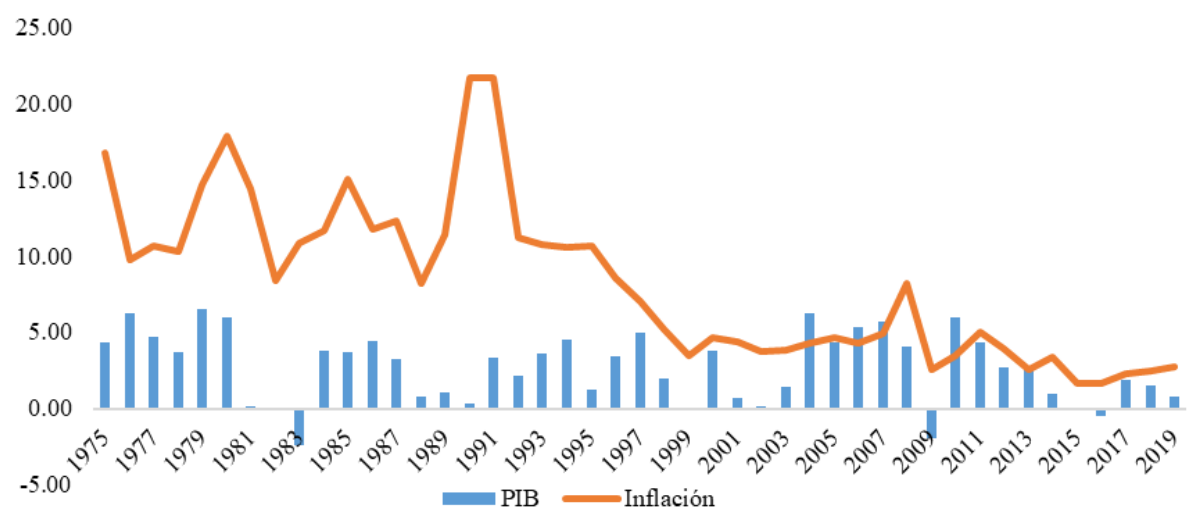

Fuente: Elaboración propia con base en Banco Mundial.

Hasta medados de la década de los años ochenta, la deuda fue un mecanismo para contribuir al financiamiento del gasto público, 
principalmente en los países en desarrollo. Esta deuda, se contrataba específicamente para crear obras de infraestructura que coadyuvaran al desarrollo económico de sus países. Sin embargo, a finales de la década de los años ochenta, la relación deuda/PIB de las economía latinoamericanas creció a niveles poco sostenibles -respecto al ingreso generado por esas economías- lo que provocó que estas economías se vieran obligadas a renegociar su deuda a un costo elevado y a plazos extensos que comprometían los ingresos públicos de los años siguientes. En este contexto, se emiten diez recomendaciones del Consenso de Washington para mitigar los efectos de este endeudamiento y que claramente benefician al capital financiero mediante mecanismos como la sobreexplotación de los trabajadores o simplemente mediante el proceso de financiarización que privilegia la acumulación mediante las finanzas en detrimento del capital productivo como argumentaba. ${ }^{4}$

A partir de la década de los años noventa, con la desregulación financiera, las fuentes de financiamiento externo se diversificaron y se contrajeron créditos con la banca privada internacional la cual se convirtió en una fuente importante de financiamiento ya que los recursos otorgados, no necesariamente tuvieron como fin el financiamiento del gasto público -con el problema que prestaban a tasas de mercado, lo cual hacía más elevado el costo de esa deuda- porque cabe resaltar que anteriormente, esta deuda se contraían con los organismos internacionales de crédito ${ }^{5}$.

A finales de la década de los años noventa, los países latinoamericanos comenzaron a adoptar el modelo de metas de inflación;

${ }^{4}$ Márquez Covarrubias, Humberto. "Pautas de la subordinación de México al capital global. Noticias de la antigüedad ideológica o novedades de la dependencia". En Darcy Tetreault y Mónica G. Chávez (Coords.), Rostros del Desarrollo Neoliberal en México. México. Ed. Universidad Autónoma de Zacatecas y Miguel Ángel Porrúa, 2020, pp. 223.

${ }^{5}$ Fondo Monetario Internacional, Banco Mundial, Banco Interamericano de Desarrollo, Banco Internacional de Reconstrucción y Fomento, Banco de Importaciones y Exportaciones, entre otros. 
Brasil, Chile y Argentina en 1999; México en 2001; Perú en 2002; Guatemala en 2005, entre otros. Sumado a esto, la autonomía de las Bancas Centrales de los países y el establecimiento de un tipo de cambio de libre flotación provocaron un cambio en la composición de la deuda ya que para cumplir con la meta inflacionaria y tasa de interés fijadas por la autoridad monetaria y mantener el tipo de cambio controlado fue necesario colocar valores gubernamentales que permitieran obtener la liquidez suficiente para alcanzar estos objetivos. En efecto, en el cuadro 1 se observa como a partir del 2001, la deuda interna es mayor a la deuda externa y particularmente a partir del 2005, en todos los casos la deuda interna supera a la deuda externa.

Guadro 1. Composición de la deuda en Latinoamérica: países seleccionados. (Estructura porcentual)

\begin{tabular}{|c|c|c|c|c|c|c|c|c|}
\hline & \multicolumn{2}{|c|}{ Argentina } & \multicolumn{2}{|c|}{ Chile } & \multicolumn{2}{|c|}{ Colombia } & \multicolumn{2}{|c|}{ México } \\
\hline & DI & $\mathrm{DE}$ & DI & $\mathrm{DE}$ & DI & $\mathrm{DE}$ & DI & DE \\
\hline 2000 & 36.42 & 63.58 & -25.89 & 125.89 & 50.54 & 49.46 & 40.07 & 59.93 \\
\hline 2001 & 41.46 & 58.54 & -7493.90 & 7593.90 & 49.86 & 50.14 & 42.27 & 57.73 \\
\hline 2002 & 36.20 & 63.80 & 2190.57 & -2090.57 & 49.62 & 50.38 & 46.64 & 53.36 \\
\hline 2003 & 42.96 & 57.04 & -148.99 & 248.99 & 50.53 & 49.47 & 47.03 & 52.97 \\
\hline 2004 & 41.65 & 58.35 & -533.10 & 633.10 & 55.42 & 44.58 & 47.64 & 52.36 \\
\hline 2005 & 52.63 & 47.37 & 116.08 & -16.08 & 64.19 & 35.81 & 53.09 & 46.91 \\
\hline 2006 & 58.86 & 41.14 & 125.07 & -25.07 & 63.48 & 36.52 & 69.05 & 30.95 \\
\hline 2007 & 57.07 & 42.93 & 263.29 & -163.29 & 66.43 & 33.57 & 77.61 & 22.39 \\
\hline 2008 & 61.82 & 38.18 & 64.04 & 35.96 & 65.78 & 34.22 & 81.94 & 18.06 \\
\hline 2009 & 62.61 & 37.39 & 83.20 & 16.80 & 66.41 & 33.59 & 64.30 & 35.70 \\
\hline 2010 & 62.79 & 37.21 & 91.20 & 8.80 & 68.83 & 31.17 & 65.29 & 34.71 \\
\hline 2011 & 66.15 & 33.85 & 90.58 & 9.42 & 69.21 & 30.79 & 64.27 & 35.73 \\
\hline 2012 & 69.53 & 30.47 & 81.50 & 18.50 & 72.18 & 27.82 & 68.89 & 31.11 \\
\hline 2013 & 70.02 & 29.98 & 86.51 & 13.49 & 71.87 & 28.13 & 67.96 & 32.04 \\
\hline
\end{tabular}




\begin{tabular}{|l|c|c|c|c|c|c|c|c|}
2014 & 69.65 & 30.35 & 91.97 & 8.03 & 68.54 & 31.46 & 67.03 & 32.97 \\
2015 & 71.45 & 28.55 & 97.69 & 2.31 & 60.81 & 39.19 & 62.84 & 37.16 \\
2016 & 65.53 & 34.47 & 99.11 & 0.89 & 63.39 & 36.61 & 57.32 & 42.68 \\
2017 & 59.24 & 40.76 & 100.00 & 0.00 & 64.29 & 35.71 & 57.98 & 42.02 \\
2018 & 51.07 & 48.93 & n.d. & n.d. & 64.27 & 35.73 & 59.53 & 40.47 \\
\hline
\end{tabular}

Fuente: elaboración propia con base en datos de Secretaría de ingresos públicos de Argentina, Ministerio de Hacienda de Chile, Banco de la República de Colombia, Secretaría de Hacienda y Crédito Público.

\section{iII. El neoliberalismo en México}

Las diez recomendaciones del Consenso de Washington fueron adoptadas por las economías latinoamericanas y particularmente en el caso de México, se llevaron a cabo las reformas estructurales pertinentes para aplicarlas y así tener las condiciones necesarias para fomentar el crecimiento y posteriormente el desarrollo económicos.

Cabe señalar que para tal fin, fueron modificados los artículos 25, 27 y 28 Constitucionales con el propósito de definir el papel del Estado en la rectoría del desarrollo nacional, de fomento al crecimiento económico, de las garantías a la propiedad de la Tierra y el papel del Banco Central.

Como consecuencia de la crisis del petróleo de finales de los años setenta y la devaluación del peso frente al dólar, el país presentó una de sus peores crisis de deuda a principios de la década de los años ochenta, hecho que obligó al entonces presidente Miguel De la Madrid a adoptar una serie de medidas que pondrían fin al llamado Estado Benefactor, transitando con esto, al modelo neoliberal.

Como se observa en la gráfica 3, pese a la adopción de estas medidas para fomentar el crecimiento, el país enfrentó hechos adversos como la caída de la Bolsa de Valores, la devaluación del peso frente al dólar, alta inflación, altas tasas de interés y mayor desempleo que impidieron que se alcanzaran el crecimiento y desarrollo 


\section{Gráfica 3. Indicadores Macroeconómicos de México 1981-1989}

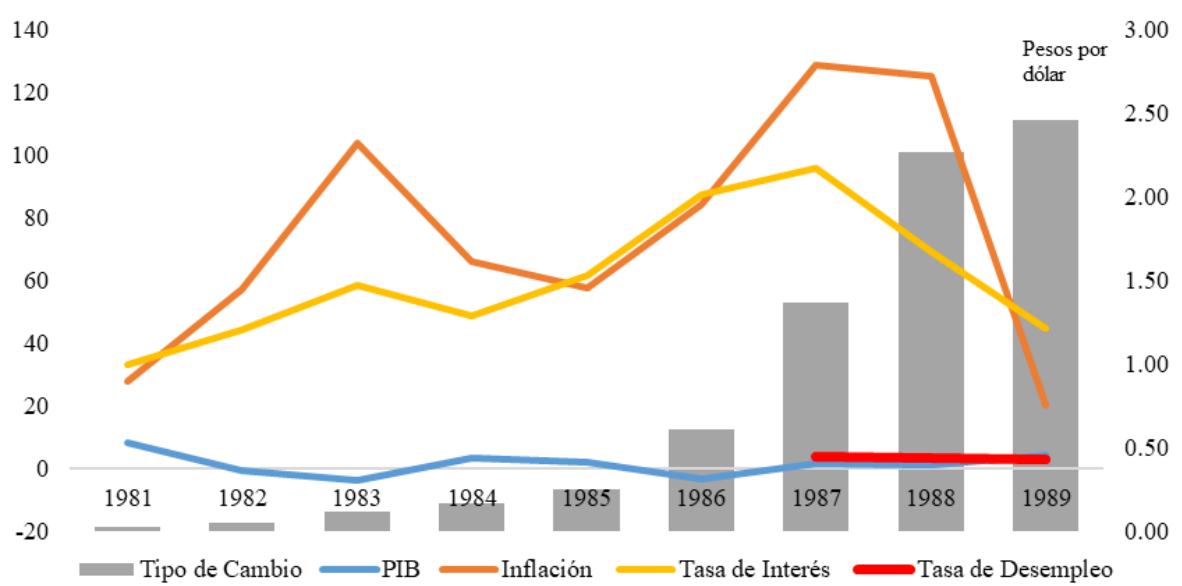

Fuente: Elaboración propia con base en Indicadores Macroeconómicos, 1980-2003. CEFP 2003

En 1988, las medidas que adoptó el gobierno del entonces presidente Carlos Salinas de Gortari para salir de la crisis económica fueron: a) renegociación de la deuda externa; b) adopción plena del modelo neoliberal mediante las recomendaciones del Consenso de Washington y; c) la firma del Pacto de Estabilidad y Crecimiento Económico el cual incluía la participación del gobierno, de las familias y del sector privado. En este contexto, el artículo 25 Constitucional establece que "Corresponde al Estado la rectoría del desarrollo nacional para garantizar que éste sea integral y sustentable, que fortalezca la Soberanía de la Nación y su régimen democrático y que, mediante la competitividad, el fomento del crecimiento económico y el empleo y una más justa distribución del ingreso y la riqueza, permita el pleno ejercicio de la libertad y la dignidad de los individuos, grupos y clases sociales, cuya seguridad protege esta Constitución... Al desarrollo económico nacional concurrirán, con responsabilidad social, el sector público, el sector social y el sector privado, sin menoscabo de otras formas de actividad económica que contribuyan al desarrollo de la Nación..."

${ }^{6}$ Para mayor información ver Constitución Politica de los Estados Unidos Mexicanos. 
Algunos autores como Ortiz argumentan que el plan gradual de estabilización macroeconómica provocó un enorme costo social sobre todo para el grupo de asalariados ya que se estima que de 1988 a 1994 la capacidad adquisitiva cayó 55\% aproximadamente. En este sentido, afirmó que este hecho benefició a los empresarios debido a que se incrementó la producción a un costo más bajo como consecuencia de esta pérdida de poder adquisitivo. ${ }^{7}$

A partir de la década de los años noventa, se empezaron a dar una serie de transformaciones jurídicas, políticas y económicas para terminar con el proceso de apertura comercial, liberalización económica y privatización de las empresas públicas. Adicionalmente, el proceso de globalización acentuó la importancia del sistema financiero a nivel nacional e internacional ya que se registró un aumento considerable en el número de transacciones a nivel mundial. En el caso de México en 1993, con las negociaciones del Tratado de Libre Comercio de América del Norte (TLCAN) fue necesario crear las condiciones para un sistema financiero sólido que brindara certidumbre a los flujos de capital que serían recibidos en el país y para este propósito se presentó la iniciativa de reforma al artículo 28 Constitucional donde se adicionó el siguiente párrafo: "El Estado tendrá un banco central que será autónomo en el ejercicio de sus funciones y en su administración. Su objetivo prioritario será procurar la estabilidad del poder adquisitivo de la moneda nacional, fortaleciendo con ello la rectoría del desarrollo nacional que corresponde al Estado. Ninguna autoridad podrá ordenar al banco conceder financiamiento. El Estado contará con un fideicomiso público denominado Fondo Mexicano del Petróleo para la Estabilización y el Desarrollo, cuya Institución Fiduciaria será el banco central y tendrá por objeto, en los términos que establezca la ley, recibir,

http://www.diputados.gob.mx/LeyesBiblio/pdf_mov/CConstitucion_Politica.pdf consultada el 19 de junio de 2020.

${ }^{7}$ Ortiz Wadgymar, Arturo. Política económica de México 1982-2000. El fracaso Neoliberal. Ed. Nuestro Tiempo S. A., México, 1998, pp. 114. 
administrar y distribuir los ingresos derivados de las asignaciones y contratos a que se refiere el párrafo séptimo del artículo 27 de esta Constitución, con excepción de los impuestos"s

La autonomía conferida al Banco de México por el artículo 28 Constitucional, trajo como consecuencia cambios importantes en la conducción de la política monetaria del país, ya que su principal responsabilidad consistió en mantener la estabilidad y poder adquisitivo de la moneda. La primera medida que se tomó fue la de cambiar el régimen de determinación del tipo de cambio al pasar a un sistema de libre flotación, el cual dejaba al mercado la fijación de su precio en función de la oferta y la demanda. Esta medida sumada al control de la inflación y la tasa de interés, provocaron un clima de certidumbre mayor para la entrada de capital al país que permitiría a la banca central tener un margen de acción mayor para el control del tipo de cambio. En efecto, la acumulación de reservas internacionales fue la estrategia que utilizó el Banco de México para estabilizar el tipo de cambio. ${ }^{9}$ Por otro lado, cabe señalar que el saneamiento de las finanzas públicas mediante la disciplina fiscal se logró ya que pasó de un déficit en 1988 a un superávit en 1991 pero que concluyó en 1994 con la crisis de ese año. ${ }^{10}$

En la gráfica 4 se observa que después de la crisis financiera de finales de 1994, las medidas de política monetaria aplicadas en esos años, comenzaron a dar resultados positivos ya que se mantuvo la estabilidad del tipo de cambio, la tasa de inflación disminuyó considerablemente y la tasa de interés se mantuvo estable y

${ }^{8}$ Constitución Política de los Estados Unidos Mexicanos. http:/ / www.diputados.gob.mx/ LeyesBiblio/pdf_mov/Constitucion_Politica.pdf consultada el 19 de junio de 2020.

${ }^{9} \mathrm{Al}$ respecto cabe señalar que las reservas internacionales están compuestas por: ingresos provenientes de la venta del petróleo, ingresos por exportaciones, remesas y actualmente, la colocación de valores gubernamentales con fines de estabilidad monetaria (Certificados de la Tesorería, Bonos de la Tesorería de la Federación, Bonos de Regulación Monetaria, entre otros).

${ }^{10}$ Otriz Wadgymar, Arturo. Política económica de México 1982-2000. El fracaso Neoliberal. México, Ed. Nuestro Tiempo S. A., 1998. pp. 22 
competitiva para hacer frente a las necesidades de financiamiento y captación de la inversión. Como resultado de este comportamiento de las principales variables monetarias, el Producto Interno Bruto (PIB) presentó una tendencia positiva y sostenida aunque no en el nivel necesario para incentivar el empleo y por lo tanto, aumentar el nivel de vida de la población.

En efecto, México aplicó las tres estrategias que son pilares del neoliberalismo: liberalización del comercio a mediados de los años ochenta, desregulación financiera y privatización de las empresas estatales en la década de los años noventa. Estos hechos generaron crisis del peso, caída de los salarios, el empleo y en consecuencia, el aumento de la pobreza en el país. ${ }^{11}$ Por lo tanto, la evaluación del nuevo modelo para la mayoría de los mexicanos no fue favorable, como se ve reflejado en la crisis del peso, el impacto a los salarios, el empleo y el aumento de la miseria

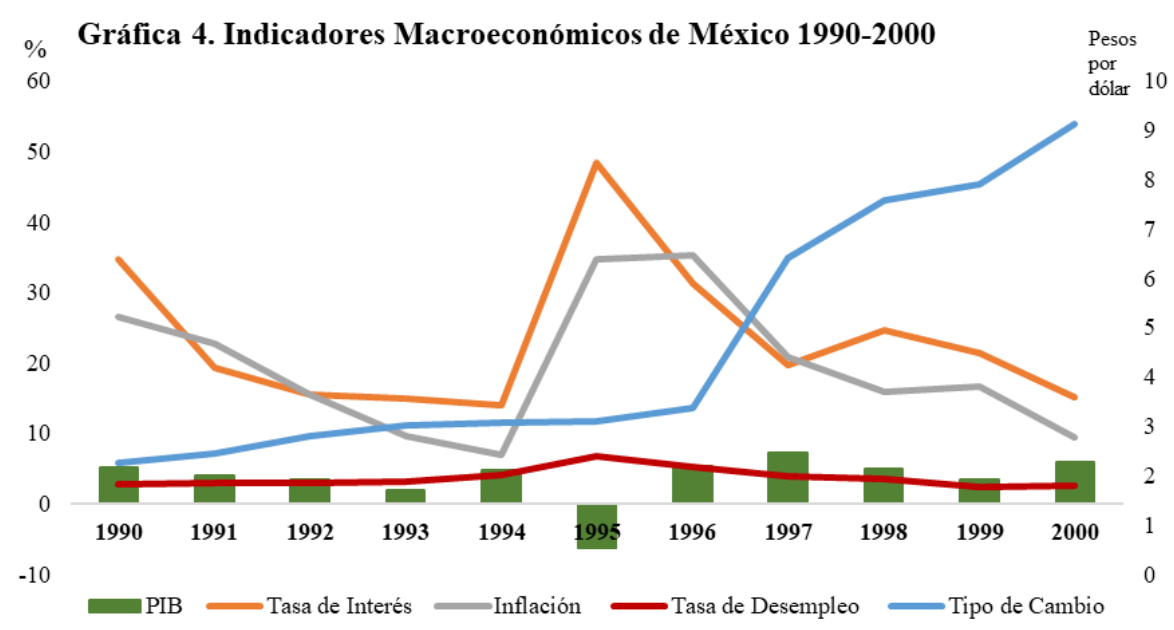

Fuente: Elaboración provia con base en Indicadores Macroeconómicos. 1980-2003. CEFP 2003

${ }^{11}$ Cooney, Pablo. "Dos décadas de Neoliberalismo en México: resultados y retos". En Novos Cadernos NAEA-Periódicos UFPA. 2008. Núm. II, diciembre, pp. 39. 
IV. El NeOliberalismo Y LA ALTERNANCIA POLÍtica EN MÉxico

En el año 2000 se presentó un hecho sin precedente en México, ya que asume la presidencia Vicente Fox Quesada candidato del Partido Acción Nacional (PAN) dando paso a la llamada alternancia política la cual desde la perspectiva neoliberal de Milton Friedman, es una condición necesaria para garantizar el éxito de la política económica de un país, como se mencionó. En este sentido, la conducción de la política económica se mantuvo sin cambios ya que el modelo continuó con el manejo de las variables monetarias, lo cual quedó de manifiesto en el 2001, cuando el Banco de México haciendo uso de los derechos que le confiere al artículo 28 Constitucional de mantener la estabilidad y poder adquisitivo de la moneda, anunció que la conducción de la política monetaria, en particular el control de los precios, estaría basado en el modelo de metas u objetivos de inflación.

El Modelo de Metas de Inflación permitió al Banco de México tener un mayor control de los precios y dar mayor certidumbre al mercado, ya que la meta inflacionaria se fijó en $3 \% \pm 1 \%$ de margen de fluctuación, medida que replicó con la tasa de interés.

La gráfica 5 muestra que esta política de fijación de precios dio resultado debido a que en el período de 2000 a 2008, la inflación y la tasa de interés se mantuvieron dentro del rango establecido situación que se vio afectada por la crisis hipotecaria hacia finales de esta década. 


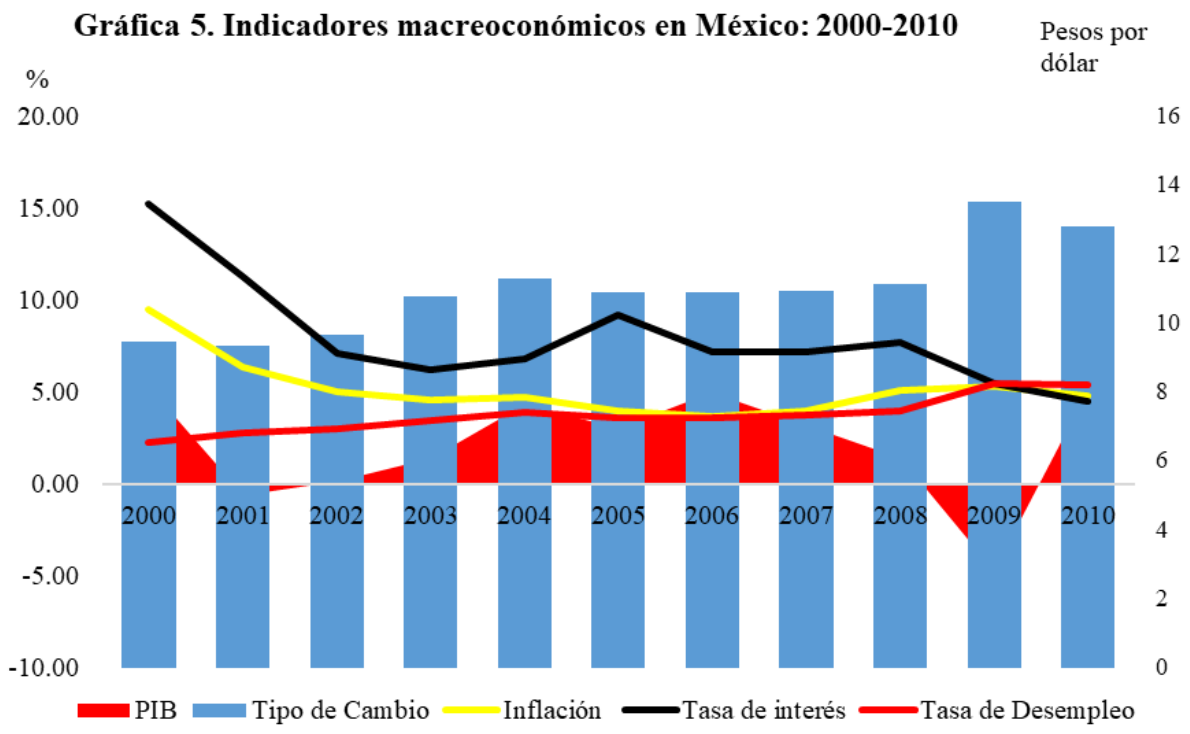

Fuente: Elaboración propia con base en Datos del Banco de México

Los efectos de la crisis hipotecaria de Estados Unidos, no se hicieron esperar en México ya que el tipo de cambio y la inflación se incrementaron como consecuencia de la inestabilidad de los mercados internacionales contagiando el mercado nacional que a su vez, se tradujo en una caída en la Bolsa de Valores y cuyo efecto final fue una contracción del crecimiento económico y el empleo, entre otras variables. En efecto, esta situación, evidencia las inconsistencias del modelo neoliberal ya que el mercado no fue capaz de reestablecer la estabilidad en las principales variables macroeconómicas -mediante el mecanismo de las libres fuerzas del mercado- ya que en países como Estados Unidos, paradójicamente fue el Estado quien intervino para evitar el cierre masivo de empresas.

En el caso de México, el gobierno no intervino para rescatar a las empresas que se vieron afectadas por esta crisis financiera, lo que provocó un incremento de la cartera vencida en los sectores, agrícola, industrial y vivienda, sectores estratégicos para dinamizar cualquier economía. En la gráfica 6 se muestra el comportamiento 
de la cartera de crédito en estos sectores antes, durante y después de la crisis de 2009. En ésta se observa una clara tendencia a la alza en la cartera vencida del crédito otorgado a estos sectores debido al problema que representó el pago de esos créditos. Por otro lado, también disminuyó el otorgamiento de estos créditos, situación que profundizó los efectos de la crisis debido a que el crédito es fundamental para incentivar la inversión y por lo tanto, el crecimiento económico.

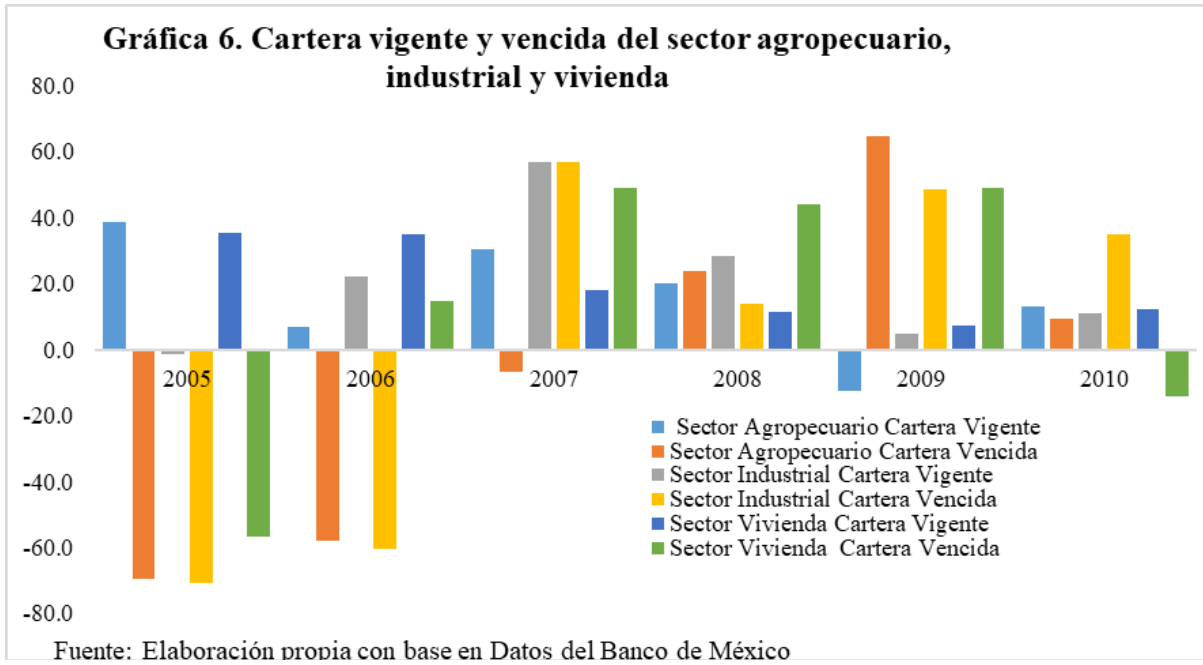

Respecto al crédito otorgado a las empresas, se observa que a partir de 2009 se reconfiguró el uso y destino del crédito solicitado por éstas, debido a que como se observa la gráfica 7, el destino del crédito se canalizó para el pago de las remuneraciones al capital de trabajo (pago de sueldos y salarios) y a la reestructuración de pasivos en detrimento de la inversión. Esto provocó que las empresas no generaran el volumen de producción necesaria para cubrir los compromisos crediticios y tampoco el capital necesario que les permitiera cubrir el pago del capital de trabajo y pasivos sin necesidad de recurrir al crédito, 


\section{Gráfica 7. Evaluación coyuntural del mercado crediticio}

90

80

70

60

50

40

30

20

10

0

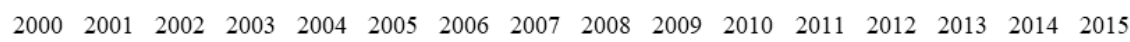

- Capital de trabajo

- Reestructuración de pasivos Inversión

Fuente: Elaboración propia con base en Datos del Banco de México

Por otro lado, ante la necesidad de financiamiento, las empresas se vieron obligadas recurrir a los proveedores y a las emisiones bursátiles para obtener los recursos para solventar sus obligaciones y poder refinanciarse y de esta forma, aumentar su ingreso ya que mediante los canales tradicionales de crédito, fue cada vez más difícil obtener este financiamiento como se muestra la gráfica 8.

\section{Gráfica 8. Estructura del financiamiento de las empresas: 2009-} 2015.

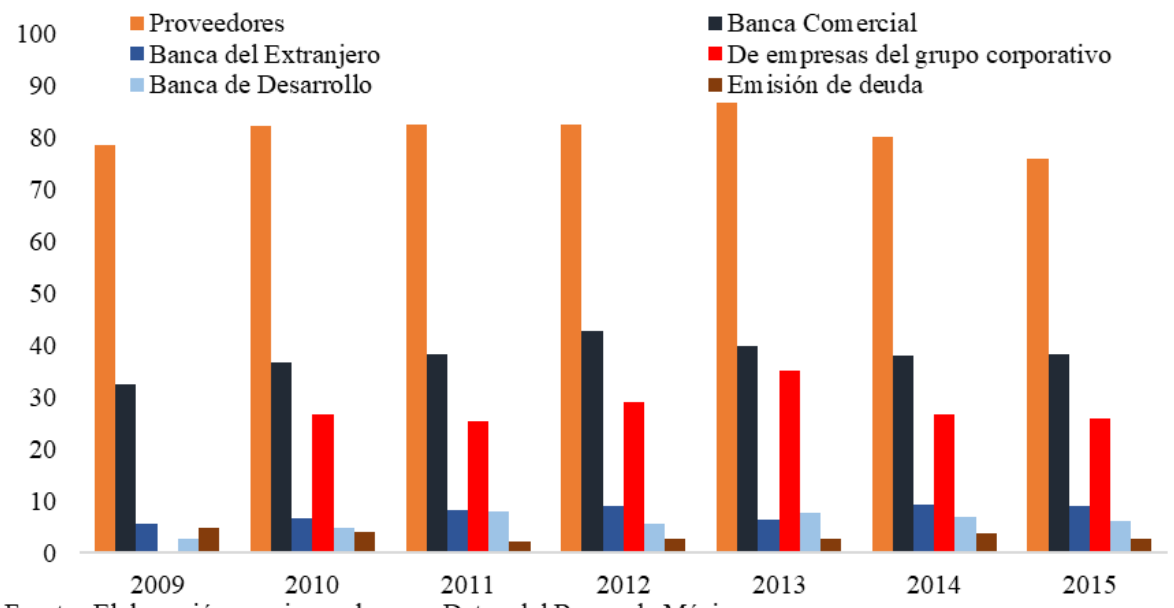

Fuente: Elaboración propia con base en Datos del Banco de México 


\section{v. Rumbo AL Fin DEL NEOLIBERALISMO}

El Banco de México continuó con su esquema de política basado en metas de inflación el cual le permitió mantener estables las variables monetarias y crecer al 2.1\% en promedio entre 2009 y 2018. Sin embargo, el costo fiscal de la estabilidad monetaria ha sido muy alto debido a que los objetivos principales de la política monetaria estuvieron centrados en mantener estable el tipo de cambio y controlar la inflación. En el caso del tipo de cambio, el Banco de México intervino en el mercado de cambios inyectando dólares para compensar el incremento en la demanda de éste, ${ }^{12}$ esto generó un proceso de esterilización monetaria debido a que las reservas monetarias en dólares sólo se pueden utilizar con fines de estabilidad monetaria como lo establece el artículo 18 de la Ley del Banco de México. ${ }^{13}$

A partir del 2009 la estructura de la deuda se modificó ya que en ese año se incrementó la deuda interna como consecuencia de la política monetaria aplicada ya que ésta se utilizó como un complemento en la captación de reservas con fines de estabilización cambiaria. En efecto, la deuda interna se utilizó como mecanismo de estabilidad monetaria como se observa en la gráfica 9.

12 Estos dólares dependen del nivel de reservas internacionales en los activos del Balance General del Banco de México.

${ }^{13}$ El artículo 18 de la Ley del Banco de México señala que: "El Banco de México contará con una reserva de activos internacionales, que tendrá por objeto coadyuvar a la estabilidad del poder adquisitivo de la moneda nacional mediante la compensación de desequilibrios entre los ingresos y egresos de divisas del país." http:/ /www.diputados. gob.mx/LeyesBiblio/pdf/74.pdf consultado el 20 de junio de 2020. 


\section{Gráfica 9. Reservas internacionales, deuda interna y externa en} México: 2000-2020

MDP

México: 2000-2020

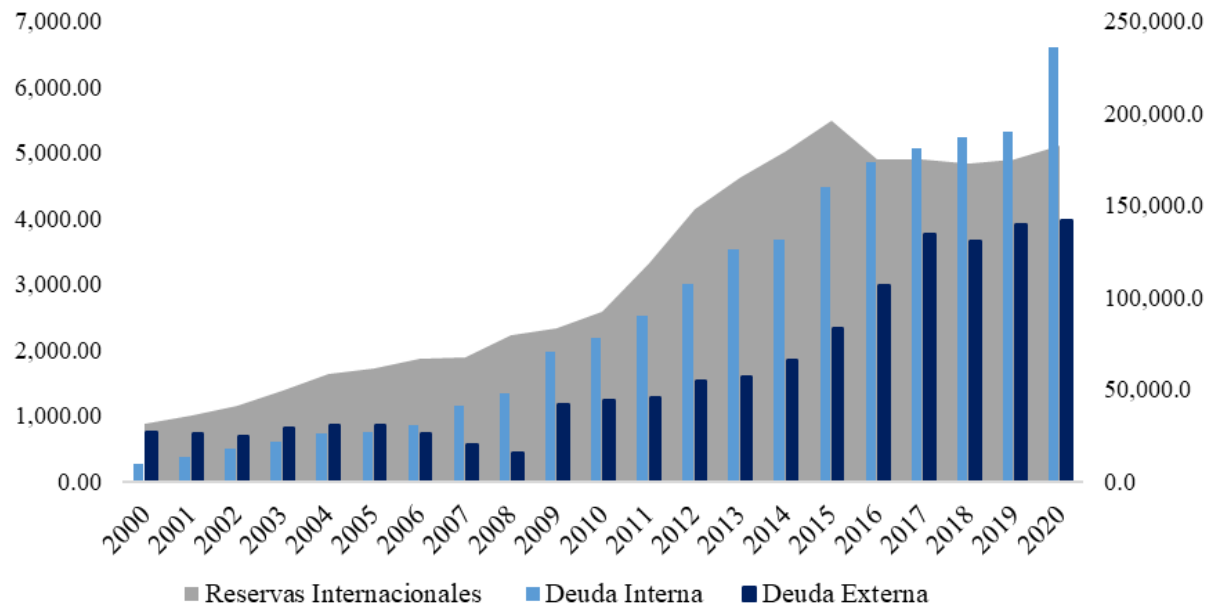

Fuente: Elaboración propia con base en Datos del Banco de México

La esterilización monetaria no permite que los activos en poder del Banco de México se canalicen hacia el sector productivo por la vía financiera mediante el crédito o a través del gasto público en inversión. En este sentido, la gráfica 10 muestra la caída en el crédito interno y el aumento de las reservas internacionales como efecto espejo, debido a que si se analiza la partida de los activos en el balance general del Banco de México, sería insostenible que tanto las reservas internacionales y el crédito interno crecieran al mismo nivel ya que no se pueden obtener los ingresos suficientes para compensar este incremento en los pasivos. 


\section{Gráfica 10. Reservas internacionales, crédito interno neto y emisión de valores en México: 1996-2018} $6,000,000.00$

$5,000,000.00$

$4,000,000.00$

$3,000,000.00$

$2,000,000.00$

$1,000,000.00$

0.00

$-1,000,000.00$

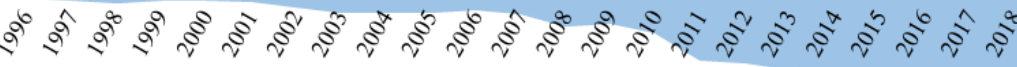

$-2,000,000.00$

$-3,000,000.00$

$$
\text { - Reserva internacionales }
$$

Crédito interno neto

-Emisión de valores

Fuente: Elaboración propia con base en Datos del Banco de México

Esta estrategia en la conducción de la política monetaria permitió que la tasa de interés, el tipo de cambio y la inflación se mantuvieran estables, pero el costo de esta estabilidad fue alto para las finanzas públicas debido a que la deuda interna provino de la colocación de valores emitidos por el gobierno federal donde a partir de este año, aumentó el costo financiero de la deuda a niveles similares e incluso superiores a los montos que se destinan a la inversión pública o gasto de capital, a las transferencias a través de los subsidios de los bienes y servicios del Estado y a las transferencias a los estados y municipios del país como se observa en la gráfica 11 .

\section{Gráfica 11. Costo financiero de la deuda y gasto de capital}

$1,400,000.00$

$1,200,000.00$

$1,000,000.00$

$800,000.00$

๓ Costo financiero de la deuda $\square$ De capital

$600,000.00$

$400,000.00$

$200,000.00$

0.00

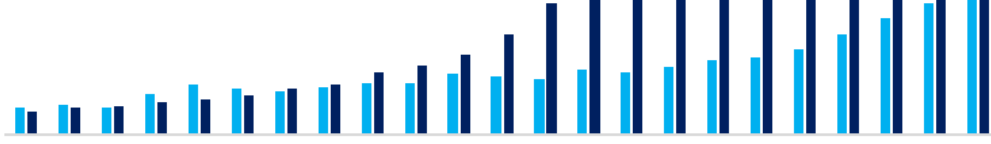

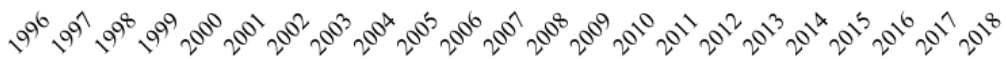

Fuente: Elaboración propia con base en Datos del Banco de México 
En efecto, la estabilidad monetaria representó un problema importante en la conducción de la política fiscal ya que ésta quedó subordinada a las necesidades de recursos que se destinaban al sistema financiero y en apoyo a la política monetaria. Adicionalmente en el año 2015, se reformó el artículo 25 constitucional donde se agregó un párrafo donde se sugiere que el Estado es el encargado de vigilar la estabilidad de las finanzas públicas y el sistema financiero, con el propósito de coadyuvar al crecimiento económico y el empleo, situación que disminuyó el margen de acción de la política fiscal para generar una mejor distribución del ingreso.

Por otro lado, otra de las variables que estimulan la economía es la inversión - pública y privada- ya que como lo establece el artículo 25 de la Constitución, el Estado impulsará a las empresas de los sectores social y privado para invertir en los distintos sectores económicos, en particular, las micro y pequeñas empresas que son las mayores generadoras de empleo en el país las cuales requieren de un mayor apoyo, pero como se mostró en la gráfica 11, los recursos se están canalizando hacia el pago de la deuda, en detrimento de la inversión productiva que a su vez, impide la canalización de recursos hacia los sectores más dinámicos de la economía. En efecto, la inversión debería ser el canal mediante el cual el gobierno debería incentivar la actividad económica para estimular el empleo y el ingreso.

Ante la persistente caída de sus ingresos, las micro y pequeñas empresas, han tomado medidas de ajuste para compensar las pérdidas y para poder continuar con el ciclo productivo, es por esto que recurren al crédito como una opción para poder continuar con sus actividades, sin embargo, como lo muestra la gráfica 12, el destino del crédito ha sido diverso como consecuencia de las necesidades de cada empresa; la reestructuración de pasivos presentó un crecimiento promedio de $8.57 \%$, mientras que la inversión disminuyó $0.67 \%$ en promedio en esta década. En este sentido, infiere que las empresas están solicitando nuevos créditos para poder cubrir con 
las obligaciones adquiridas con anterioridad, lo que vulnera su capacidad de pago ya que de continuar con esta tendencia, podrían presentar problemas de cartera vencida como ha sucedido en otras ocasiones.

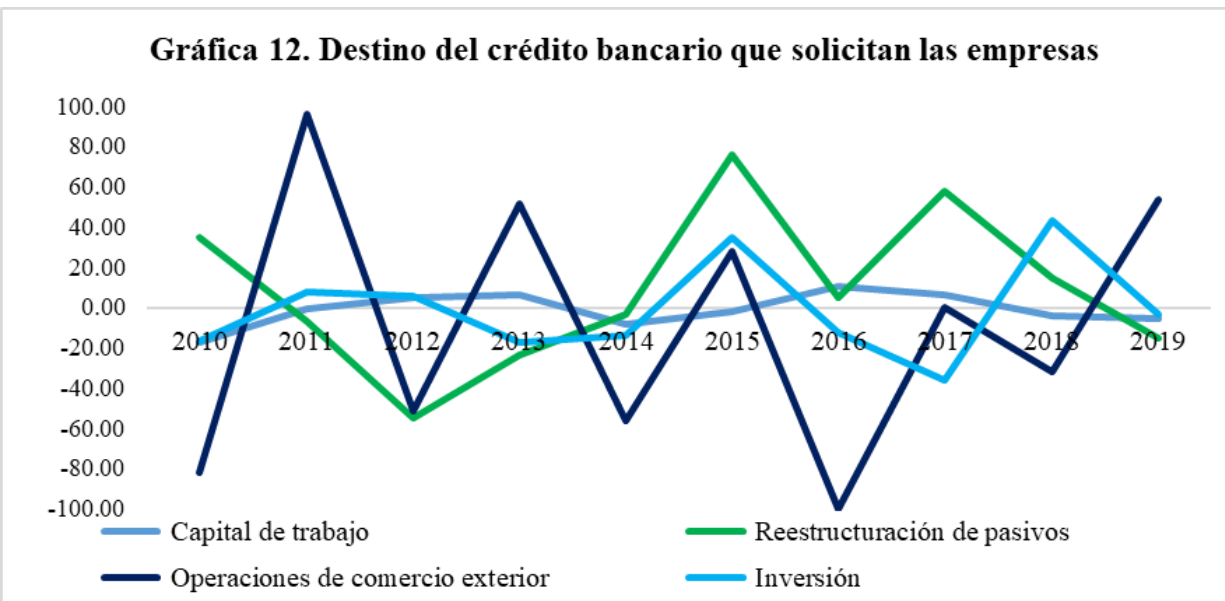

Fuente: elaboración propia con base en datos del Banco de México

Vi. El NeOliberalismo un Experimento Fallido EN MÉxICO: ENTRE EL DEBER Y EL SER.

El artículo 25 Constitucional enmarca la directriz respecto a la política económica que se debe implementar para garantizar el desarrollo nacional mediante la correcta distribución de la riqueza, a través del gasto público, ya que éste permitiría asignar recursos que se verían reflejados en mejoras en los servicios públicos como educación, salud, seguridad, vivienda entre otros y que son considerados como elementos que propician un nivel de desarrollo en la población. Además con la promoción del crecimiento económico se pretendía generar un mayor nivel de empleo que permitiría a los individuos tener los recursos necesarios para satisfacer sus necesidades primarias y de esta forma promover la competencia entre los distintos actores económicos, que es una condición necesaria para el correcto funcionamiento del modelo neoliberal. 
Sin embargo, esto no ha sido así debido a partir de 1988 cuando oficialmente se adoptó este modelo en México, si bien se han alcanzado niveles de estabilidad macroeconómica ha sido en detrimento del nivel de vida de la población y la distribución del ingreso generando con esto, una concentración de la riqueza en poder de unos cuantos.

De acuerdo con datos del Banco Mundial, el combate a la pobreza ha sido insuficiente ya que como lo muestra la gráfica 13 la pobreza extrema en el país ha tenido un crecimiento promedio 40 . $86 \%$ de 2000 a 2018, lo cual evidencia el fracaso del modelo neoliberal en México induciendo a la búsqueda de un modelo alternativo que permita revertir estos efectos en la economía nacional.

\section{Gráfica 13. Pobreza en México: 2000-2018}

$$
\begin{aligned}
& 50 \\
& 45 \\
& 40 \\
& 35 \\
& 30 \\
& 25 \\
& 20 \\
& 15 \\
& 10 \\
& 5
\end{aligned}
$$$$
0
$$

2000
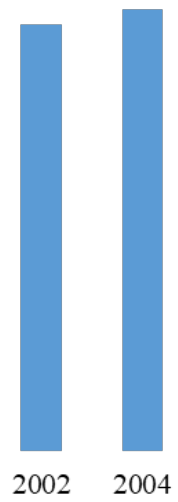
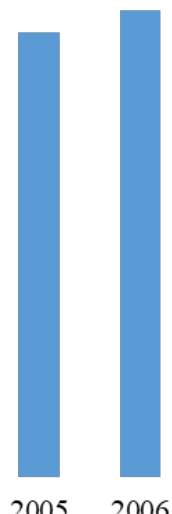
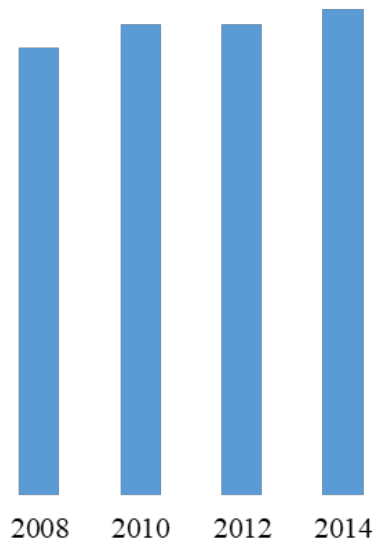

20122014

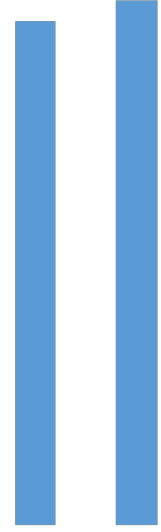

20162018

Fuente: Elaboración propia con base en Datos del Banco Mundial

Al respecto, García-Bedoy argumenta que han sido muchas las consecuencias del modelo neoliberal que se aplicó en México a partir de la década de los años ochenta, tales como: bajos salarios, mayor desempleo, alta concentración de la riqueza, profundización de la pobreza; daños, quiebras y cierre de la micro, pequeña y mediana 
industria, y una mayor dependencia económica del exterior, sobre todo de Estados Unidos. ${ }^{14}$

En el contexto actual de la llamada cuarta transformación, donde uno de los argumentos centrales ha sido no recurrir al endeudamiento externo para financiar el gasto público, la promoción de la austeridad y el combate a la corrupción, si bien el nivel de deuda interna no ha crecido considerablemente como se observa en la gráfica 14, el Banco de México sigue utilizando la emisión de valores (deuda interna) como un mecanismo de control a las fluctuaciones del tipo de cambio.

\footnotetext{
$7,300,000.0$

$7,100,000.0$

$6,900,000.0$

$6,700,000.0$

$6,500,000.0$

$6,300,000.0$

$6,100,000.0$

$5,900,000.0$

$5,700,000.0$

$5,500,000.0$
}

Gráfica 14. Deuda interna en México

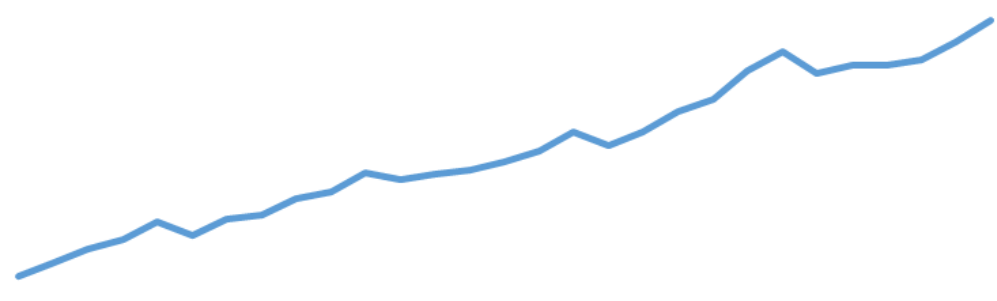

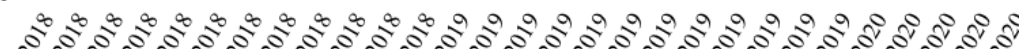

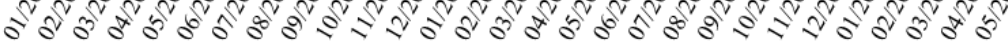

Fuente: elaboración propia con base en datos de la SHCP.

Por otro lado, como se muestra en la gráfica 15, este gobierno ha utilizado el impuesto sobre la renta (ISR) como el principal elemento compensatorio de los flujos de ingreso, mediante un sistema de recaudación que ha eliminado algunas deducciones para personas físicas y morales que sumado al impuesto al valor agregado (IVA), han proporcionado los recursos mínimos necesarios para ejecutar los programas prioritarios de este gobierno, sin recurrir al financiamiento externo pero sin que sea suficiente para promover el crecimiento económico.

${ }^{14}$ García-Bedoy, Humberto. Neoliberalismo en México: características, límites y consecuencias. Jalisco, México. Centro de reflexión y acción social. X Centro de Reflexión Teológica. ITESO. 1992. Pp. 73-128 
Como se observa en la gráfica 15, el ISR representó en los últimos meses - marzo, abril y mayo de 2020- cerca del 60\% del total de los ingresos tributarios en México; y la suma de lo recaudado por concepto de ISR e IVA en el mismo periodo fue de $85 \%$ en promedio.

\section{Gráfica 15. Impuesto sobre la renta e impuesto al valor agregado. (Estructura porcentual)}

Fuente: elaboración propia con base en datos de la SHCP

A partir de marzo de 2019 el Presidente Andrés Manuel López Obrador declaró el final del modelo neoliberal expresando también que en una 'economía para el bienestar', el mercado no puede sustituir al Estado. La política del actual gobierno, pretende incrementar el nivel del gasto público y con esto incentivar el crecimiento de la demanda agregada mediante un incremento en los recursos hacia los programas sociales, con el objetivo de proveer de ingresos a los que menos tienen -por ejemplo, en el año de 2020 se destinaron alrededor de 1.3 billones de pesos para este propósito-.$^{15}$

Hipotéticamente, este tipo de apoyos son benéficos ya que permiten que las personas con los niveles de ingreso más bajos tengan un complemento para satisfacer sus necesidades; sin embargo, esto

${ }^{15}$ Información obtenida de la página: https://www.transparenciapresupuestaria. gob.mx/es/PTP/infografia_ppef2020 
ha provocado que se relegue la inversión de capital y el apoyo a las micro y pequeñas empresas que es donde se concentra la mayor cantidad de personas empleadas en el país, y que en estos últimos años ha propiciado una caída en la actividad económica; panorama que no mejorará en 2020 debido a la crisis sanitaria ya que la caída prevista por la Secretaría de Hacienda y Crédito Público es de 3.9\% y por el Banco de México oscila entre 4.6 y hasta $8.8 \%$.

El actual gobierno intenta retomar algunos postulados keynesianos del estado benefactor incrementando el gasto público para distribuir el ingreso del país a través de un incremento en los programas sociales los cuales incluso han sido elevados a rango constitucional con la finalidad de proveer recursos a los beneficiarios de estos programas. Al respecto, Salazar argumenta que la ejecución del gasto se debe realizar de una forma adecuada y canalizarse hacia programas de transferencias y servicios sociales pero también hacia promoción de las capacidades productivas. ${ }^{16}$

La emergencia sanitaria, la contracción de la actividad económica mundial, los bajos niveles de inversión extranjera, la inestabilidad bursátil, la caída en el empleo, la caída de los precios del petróleo entre otros, limitan el margen de acción de cualquier tipo de política económica que se adopte para alcanzar los objetivos de desarrollo y bienestar debido a que el gobierno deberá generar los ingresos suficientes a través del correcto funcionamiento de la economía para el crecimiento y desarrollo en México. En este sentido, Salazar afirma que "no hay forma de pensar que vamos a estar en una sociedad mejor, más igualitaria, si hay un creciente nivel de desempleo en el país. Decir que debemos ir (hacia otros indicadores) me parece muy oportuno políticamente cuando tu economía probablemente decrezca 7 u 8 por ciento". ${ }^{17}$

${ }^{16}$ Salazar López, César Armando. "Gasto público y crecimiento económico: Controversias teóricas y evidencia para México. En ECONOMÍAunam, vol.17, núm 50, mayo agosto 2020, pp. 69, México.

${ }^{17}$ Salazar López, César Armando; en Villanueva Dora. Polémico pedir que el concepto 
En este contexto, la economía nacional cuenta con un marco jurídico en el cual establece que es el Estado con el sector social y el sector privado los que de manera responsable participarán en el desarrollo nacional, es decir, el deber ser en México está perfectamente delimitado y normado para estos propósitos pero el ser, no ha sido debido a que intervienen factores externos que provocan inestabilidad y desequilibrios que no pueden ser previstos y controlados por las instituciones. Por lo tanto, el gran reto de cualquier gobierno es fusionar el aparato jurídico, político y económico para lograr los objetivos de crecimiento y desarrollo económicos y en la actualidad, el llamado bienestar para la población mexicana. A casi dos años de que inició el sexenio de Andrés Manuel López Obrador no es claro el cambio en la dirección de la política económica para la generación de expectativas para el crecimiento económico nacional. Sin embargo, está presente la posibilidad de que en los cuatro años restantes de este gobierno, se creen las condiciones de crecimiento económico para que en el mediano plazo se pueda aumentar el nivel de vida de la población.

\section{Vil. Conclusiones}

Los economistas clásicos fueron los primeros en plantear la idea de libre mercado y la escasa participación del Estado en la actividad económica, mismas que fueron retomadas por Friedrich Von Hayek en donde es el mercado el que regula la actividad económica, distribuye de forma eficiente los recursos y el Estado es el que debe garantizar el estado de derecho mediante un marco jurídico que brinde certidumbre a los actores de la economía.

Milton Friedman dejó claro que es la política monetaria la herramienta que permite al Estado garantizar el crecimiento económico mediante el control de los precios, la tasa de interés y la cantidad

del PIB debe entrar en desuso. En La Jornada https: / /www.jornada.com.mx/2020/05/10/ economia, México, 10 de mayo de 2020, consultado el 03 de junio de 2020. 
de dinero en circulación subordinando a la política fiscal a los objetivos de control monetario a diferencia de lo planteado por Keynes quien se pronunció a favor de un mayor gasto público para incentivar el crecimiento de la demanda agregada y en consecuencia, el crecimiento económico y el empleo.

En México la adopción del modelo neoliberal se dio de forma gradual, iniciando a principios de los años ochenta como resultado de la crisis de deuda externa y materializándose en 1989 con la implementación de las recomendaciones del Consenso de Washington con el propósito de estabilizar la economía y sentar las bases de un crecimiento económico sostenido y de largo plazo. Sin embargo, después de varias décadas de este modelo se ha reflejado el fracaso, porque a pesar de tener estabilidad macroeconómica no logró alcanzar el objetivo de mejorar el nivel de vida de la población, por el contrario, profundizó la desigualdad y marginación de un importante sector de la población del país.

El gobierno actual dio fin al llamado modelo neoliberal pero el principal reto al que se enfrenta es el de generar las condiciones de certidumbre para que el sector social y el sector privado participen de manera activa en la actividad económica del país y con ello, fomentar el desarrollo y bienestar que son los objetivos prioritarios en su 'nueva política económica' que denominó como posneoliberal. Guenta con el marco jurídico e institucional para conducir la economía bajo estas directrices, el gran reto que enfrenta este gobierno es hacer frente a los desequilibrios provenientes del exterior, sobre todo en el contexto actual, para incentivar la inversión que genere un incremento en el empleo e ingresos para la población y el Estado y con esto incentive el crecimiento y desarrollo económicos. 
Vili. Fuentes consultadas

\section{Bibliografía}

García-Bedoy, Humberto, Neoliberalismo en México: características, límites y consecuencias, Jalisco, Centro de reflexión y acción social, X Gentro de Reflexión Teológica, ITESO, 1992.

Hayer, Friedrich Von, Camino de Servidumbre. Ed. Alianza Editorial. 2011. España.

Keynes, J. M., Teoría General de la Ocupación, el Interés y el Dinero, México, Ed. FGE, 2000.

Márquez Covarrubias, Humberto, "Pautas de la subordinación de México al capital global. Noticias de la antigüedad ideólogica o novedades de la dependencia", en Darcy Tetreault y Mónica G. Chávez (Coords.), Rostros del Desarrollo Neoliberal en México, México, Universidad Autónoma de Zacatecas y Miguel Ángel Porrúa. 2020.

Otriz Wadgymar, Arturo, Política económica de México 1982-2000. El fracaso Neoliberal, México, Nuestro Tiempo S. A., 1998.

\section{Hemerografía}

Cooney, Pablo, "Dos décadas de Neoliberalismo en México: resultados y retos", en Novos Cadernos NAEA-Periódicos UFPA, 2008, Núm. 2, vol. 11, diciembre.

Salazar López, César Armando, "Gasto público y crecimiento económico: Controversias teóricas y evidencia para México". En ECONOMÍAunam, Giudad de México, 2020. Núm. 50, vol.17, mayo agosto, pp. 69.

, César Armando, en Villanueva Dora, "Polémico pedir que el concepto del PIB debe entrar en desuso", en La fornada 
https://www.jornada.com.mx/2020/05/10/economia, México, 10 de mayo de 2020.

Williamson, John, "What Washington Means by Policy Reform", en Latin American Adjustment: How Much Has Happened?, 1990, https://www.piie.com / commentary/speeches-papers / what-washington-means-policy-reform.

\section{Electronicas}

Banco de la República de Colombia. https://www.banrep.gov.co/.

Banco de México: estadísticas. Sistema de Información Económica. https://www.banxico.org.mx/.

Banco Mundial https://www.bancomundial.org/.

Cámara de Diputados, Centro de Estudios de las Finanzas Públicas, Indicadores Macroeconómicos, 1980-2003, https://www.cefp.gob. $\mathrm{mx} / \mathrm{intr} /$ edocumentos/pdf/cefp/cefp0302003.pdf.

Constitución Política de los Estados Unidos Mexicanos. http://www.diputados.gob.mx/LeyesBiblio/pdf_mov/Constitucion_Politica. pdf.

Ley del Banco de México http://www.diputados.gob.mx/LeyesBiblio/ pdf/74.pdf.

Ministerio de Hacienda de Chile, https://www.gob.cl/ministerios/ministerio-de-hacienda/.

Secretaría de Hacienda y Crédito Público. http://presto.hacienda.gob. $\mathrm{mx} /$ EstoporLayout/estadisticas.jsp.

Subsecretaría de ingresos públicos de Argentina. https://www.argentina. gob.ar/economia/ingresospublicos. 